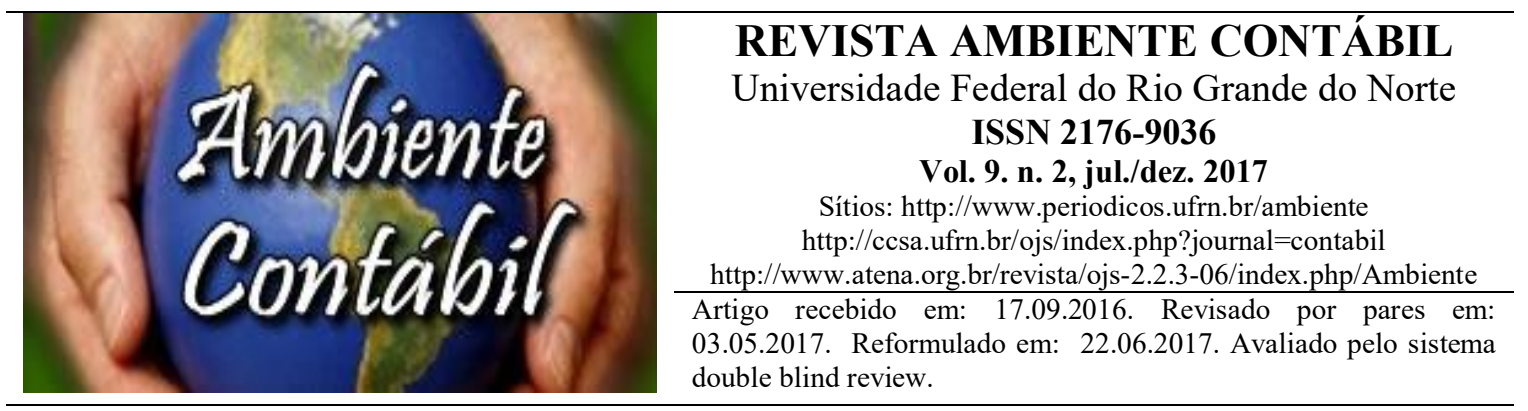

\title{
A INFLUÊNCIA DO DISCLOSURE VOLUNTÁRIO NO CUSTO DA DÍVIDA DE FINANCIAMENTOS EM EMPRESAS LISTADAS NA BM\&FBOVESPA
}

\section{THE INFLUENCE OF VOLUNTARY DISCLOSURE ON COST OF FINANCING DEBT IN LISTED BRAZILIAN COMPANIES IN BM\&FBOVESPA}

\section{LA INFLUENCIA DE LA REVELACIÓN VOLUNTARIA DE INFORMACIÓN SOBRE EL COSTE DE FINANCIACIÓN DE LA DEUDA DE COMPAÑÍAS REGISTRADAS EN EL BRASILEÑO BM \& FBOVESPA}

Autores

Claudio Marcelo Edwards Barros

Professor da Universidade Federal do Paraná. Doutorado em andamento em Contabilidade e

Finanças na Universidade Federal do Paraná. Mestre em Contabilidade e Finanças pela Universidade Federal do Paraná. Setor de Ciências Sociais Aplicadas, $1^{\circ}$ Andar. Endereço: Av. Prefeito Lothário Meissner, 632 - Jardim Botânico - CEP: 80210-070 - Curitiba - PR Brasil - Telefone: (41) 3041-3182. Identificadores (ID):

Lattes: http://lattes.cnpq.br/8486915444145984 E-mail: claudiomedwards@hotmail.com

Sonia Raifur Kos

Professora da Universidade Estadual do Centro Oeste. Doutoranda em Contabilidade pela Universidade Federal do Paraná - UFPR. Mestre em Contabilidade e Finanças pela Universidade Federal do Paraná. Setor de Ciências Sociais Aplicadas, $1^{\circ}$ Andar. Endereço: Av. Prefeito Lothário Meissner, 632 - Jardim Botânico - CEP: 80210-070 - Curitiba - PR Brasil - Telefone: (41) 3041-3182. Identificadores (ID): Lattes: http://lattes.cnpq.br/1211174426241413 E-mail: soniarkos@yahoo.com.br

Silvia Consoni

Professora do Departamento de Ciências Contábeis da Universidade Federal do Paraná. Doutoranda do Programa de Pós-Graduação em Contabilidade da UFPR. Mestre em Contabilidade e Finanças pela Universidade Federal do Paraná. Setor de Ciências Sociais Aplicadas, $1^{\circ}$ Andar. Endereço: Av. Prefeito Lothário Meissner, 632 - Jardim Botânico - CEP: 80210-070 - Curitiba - PR - Brasil - Telefone: (41) 3041-3182. 
Identificadores (ID):

Lattes: http://lattes.cnpq.br/1153315249969383

ORCID: http://orcid.org/0000-0002-3967-7006

ResearcherID: http://www.researcherid.com/rid/G-4946-2017

Research Gate: https://www.researchgate.net/profile/Silvia_Consoni2

E-mail: silviaconsoni@yahoo.com.br

Romualdo Douglas Colauto

Pós-Doutor em Controladoria e Contabilidade pela FEA/USP. Doutor e Mestre em Engenharia de Produção na Área de Gestão de Negócios pela UFSC (2005). Coordenador do Programa de Pós-Graduação em Contabilidade PPGOCNT-UFPR (Mestrado e Doutorado). Setor de Ciências Sociais Aplicadas, $1^{\circ}$ Andar. Endereço: Av. Prefeito Lothário Meissner, 632 - Jardim Botânico - CEP: 80210-070 - Curitiba - PR - Brasil - Telefone: (41) 3041-3182. Identificadores (ID):

Lattes: ttp://lattes.cnpq.br/4411504880578074

Research Gate: https://www.researchgate.net/profile/Romualdo_Colauto Google Citations: https://scholar.google.com/citations?user=y7ZmGWcAAAAJ\&hl=pt-BR E-mail: rdcolauto.ufpr@gmail.com

[Artigo apresentado no congresso USP de Contabilidade e Controladoria do ano de 2015].

\begin{abstract}
RESUMO
Decisões empresariais direcionadas a aumentar o nível de evidenciação voluntária podem exercer influência sobre o custo de capital. Neste sentido, o objetivo desta pesquisa é identificar o efeito do disclosure voluntário sobre custo da dívida de financiamentos de curto e longo prazo em empresas listadas na BM\&FBOVESPA. A justificativa para este estudo foi propiciar uma abordagem alternativa para o exame do custo de capital de terceiros. Nesta pesquisa, diferente de estudos anteriores, não se utiliza a despesa financeira presente na Demonstração do Resultado do Exercício como proxy para o custo da dívida $\left(K_{e}\right)$, mas sim as despesas com juros que compõe a remuneração de capital de terceiros apresentada na Demonstração do Valor Adicionado (DVA). A amostra da pesquisa compreendeu 57 empresas brasileiras. Para alcançar o objetivo proposto, utilizou-se como variável dependente o custo da dívida $\left(\mathrm{K}_{\mathrm{e}}\right)$ e como variável independente o Índice de Divulgação Voluntária (IDV) proposto por Consoni e Colauto (2016). Como método estatístico de estimação de parâmetros foi utilizado Regressão Linear Múltipla em mínimos quadrados ordinários (MQO) e mínimos quadrados generalizados (MQG) combinado com o exame de presença de outliers multivariados por meio da distância de Mahalanobis. Os resultados sugerem que, embora as empresas da amostra apresentem diferenças em níveis de evidenciação espontânea e também diferenças de custo de financiamento, não foram identificados indícios de que a divulgação voluntária influencia negativamente o custo da dívida. O estudo é importante porque apresenta como novidade a utilização do custo da dívida obtido a partir da DVA, além de um tratamento para observações desviantes.
\end{abstract}

Palavras-chave: Custo de dívida. Disclosure voluntário. Demonstração do Valor adicionado. 


\begin{abstract}
Corporate decisions directed to increase voluntary disclosure level may influence the cost of capital. In this sense, the objective of this research is to identify the effect of voluntary disclosure on debt cost of short and long-term financing in companies listed on the BM \& FBOVESPA. The rationale for this study is to provide an alternative methodological approach to the examination of third-party capital cost. In this study, unlike previous studies, it is not uses financial expenses present in Income Statement (DRE) as proxy for the cost of debt $\left(\mathrm{K}_{\mathrm{e}}\right)$, but interest expenses that make up the third-party capital remuneration in the Value Added Statement (DVA). The sample comprises 57 Brazilian companies. To achieve the proposed goal, it was used as the dependent variable debt cost $\left(\mathrm{K}_{\mathrm{e}}\right)$ and as the independent variable the voluntary disclosure index (IDV) proposed by Consoni e Colauto (2016). As statistical method of parameter estimation, it was used multiple linear regression for ordinary least squares (OLS) and generalized least squares (GLS) combined with examination of the presence of multivariate outliers by Mahalanobis distance. The results suggest that although the sample companies differ in levels of spontaneous disclosure and also differences in the cost of financing, indications were identified that voluntary disclosure would adversely affect the cost of debt. The study is relevant because it presents as a novelty the use of debt service costs obtained from the DVA.
\end{abstract}

Keywords: debt cost. Voluntary Disclosure. Added Value Statement.

\title{
RESUMEN
}

Las decisiones corporativas dirigidas para aumentar el nivel de información voluntaria puede influir en el costo del capital. En este sentido, el objetivo de esta investigación es identificar el efecto de la revelación voluntaria en el precio de la deuda de la financiación a corto y largo plazo en las empresas que figuran en la BM \& FBOVESPA. La justificación de este estudio es proporcionar un enfoque metodológico alternativa al examen de costo de capital de terceros. En este estudio, a diferencia de los estudios anteriores, no se utiliza gastos financieros presentes en el Estado de Resultados (DRE) de proxy para el costo de la deuda $\left(\mathrm{K}_{\mathrm{e}}\right)$, pero los gastos de interés Que componen la remuneración del capital de terceros en la Declaración sobre el Valor Añadido ( DVA). La muestra compreende 57 empresas brasileñas. Para lograr el objetivo propuesto, se utilizó el costo variable dependiente de la deuda $\left(\mathrm{K}_{\mathrm{e}}\right)$ y la variable independiente del índice de divulgación voluntaria (IDV) Propuesto por Consoni e Colauto (2016). El método estadístico de estimación de parámetros, se utilizó la regresión lineal múltiple de mínimos cuadrados ordinarios (MCO) y mínimos cuadrados generalizados (MCG) combinado con el examen de la presencia de valores atípicos multivariantes por la distancia de Mahalanobis. Los resultados sugieren Que aunque las compañías de la muestra difieren en los niveles de divulgación espontánea y también diferencias en el coste de la financiación, las indicaciones fueron identificados Que la revelación voluntaria afectaría negativamente al coste de la deuda. El estudio es relevante debido a que presenta como novedad el uso de los costos del servicio de la deuda obtenido de la DVA.

Palabras clave: El coste de la deuda. La divulgación voluntaria. Añadido Declaración de Valor.

Revista Ambiente Contábil - ISSN 2176-9036 - UFRN - Natal-RN. v. 9. n. 2, p. 334 - 354, jul./dez. 2017. 


\section{INTRODUÇÃO}

A divulgação voluntária, definida por Gibbins, Richardson e Waterhouse (1990) como um comportamento estratégico das empresas, tem o potencial de reduzir a assimetria de informação e, consequentemente, permitir aos provedores de capital melhor avaliar as oportunidades de investimento e monitorar o uso dos recursos comprometidos. Healy e Palepu (2001) comentam que a procura por fundos adicionais pelas empresas aumenta quando surgem novas oportunidades de investimento e, por isso, existem incentivos para a divulgação de informações, uma vez que a persistência de assimetria informacional leva, ex ante, ao problema de seleção adversa e, ex post, ao problema do risco moral.

O custo de capital é o retorno mínimo exigido pelos investidores para disponibilizar seus recursos em um novo projeto. Do ponto de vista teórico a política de divulgação voluntária pode influenciar o custo das fontes de financiamento empresarial (VERRECCHIA, 2001; DYE, 2001). Embora existam evidências empíricas inconclusivas sobre esse aspecto (BOTOSAN, 2006), outras demonstram que a divulgação voluntária e o custo de capital estão inversamente relacionados (SENGUPTA, 1998; MAZUNDAR; SENGUPTA, 2005; LIMA, 2009; LOPES; ALENCAR, 2010). Tais pesquisas assumem que o custo de capital é uma medida que capta o quão bem a divulgação voluntária das empresas atinge sua função primária de fornecer informações relevantes que melhoram a alocação de recursos o que, por sua vez, resulta em um funcionamento mais eficiente dos mercados de capitais.

Sengupta (1998) e Lima (2009), ao explorarem a questão da influência do nível de disclosure voluntário sobre o custo de capital de terceiros, observaram comportamento de direção inversa entre o custo da dívida e práticas de disclosure voluntário. Para o mercado norte-americano, Sengupta (1998) constatou que políticas de disclosure voluntário em níveis qualitativamente mais elevados diminuem a taxa de juros de carregamento de financiamentos. Lima (2009) encontrou relação inversa entre o nível de disclosure voluntário e o custo de capital de terceiros no mercado brasileiro nos anos de 2000 a 2004. Ainda que os instrumentos de pesquisa utilizados por Sengupta (1998) e Lima (2009) para mensurar e comparar empresas em termos de disclosure voluntário tenham sido diferentes, ambos utilizaram despesas com juros como proxy para o custo da dívida.

Lima (2009) representou o custo da dívida por meio das despesas financeiras presentes na Demonstração do Resultado do Exercício. No entanto, no caso brasileiro, o uso das despesas financeiras para representar o custo de dívida pode apresentar viés de superavaliação já que esta rubrica contábil também é utilizada para computar despesas com remuneração de capital próprio. A remuneração de capital próprio representa a remuneração de acionistas sob a forma de dividendos e juros sobre o capital próprio (JCP), além dos lucros retidos. Tendo em vista que os juros sobre capital próprio representam a remuneração de capital próprio e juros de financiamentos representam a remuneração de terceiros, as despesas financeiras podem não medir adequadamente o custo de dívida de uma corporação brasileira.

A remuneração de capital de terceiros refere-se a remuneração dos financiadores e detentores de bens de capital utilizados pela entidade por meio de juros e aluguéis (COSENZA, 2003). Iudícibus et al. (2010) observam que as variações cambiais passivas relativas a empréstimos também devem ser computadas como despesas financeiras e compõe o conjunto de contas que formam a remuneração de capital de terceiros. Quando Lima (2009) concluiu haver relação inversa entre custos de dívida e nível de disclosure, utilizou as despesas financeiras como proxy provavelmente em função de não haver disponível uma 
rubrica comparável e sistematizada para examinar exclusivamente os reflexos do passivo oneroso, e este aspecto representa uma limitação de sua pesquisa.

Em investigação realizada por Santos (2007) foi constatado que $42 \%$ da amostra de empresas listadas e não listadas utilizaram o recurso dos juros sobre capitais próprios no período de 1996 a 2005. Entre 2003 e 2005, mais de 42\% das companhias remuneraram capitais próprios utilizando o recurso dos JCP com valores de R $\$ 4,7$ bilhões, R $\$ 5,9$ bilhões e 7,1 bilhões, respectivamente aos anos. Santos e Salotti (2009) examinaram a percepção de 388 dirigentes de empresas brasileiras sobre o instituto dos juros sobre capital próprio para remuneração de proprietários. Uma das conclusões foi que em $95 \%$ das empresas pesquisadas houve a compensação de dividendos, referindo-se ao pagamento de JCP. Este achado realça que, embora o pagamento de juros sobre capital próprio seja opcional e dependa do lucro gerado pela corporação, houve elevada frequência de empresas brasileiras que usam o JCP como alternativa ao pagamento de dividendos. Por consequência, em um número elevado de empresas a rubrica de despesas financeiras tem em seu cômputo despesas que não são custos de financiamento externo, corroborando para a possível superavaliação das despesas financeiras como proxy para custo de dívida.

Desde 2007, a Lei 6.404/76, alterada pela Lei 11.638/2007 (BRASIL, 1976), obrigou as empresas listadas na BM\&FBOVESPA a divulgarem a Demonstração do Valor Adicionado (DVA). Nesta demonstração foi estabelecida a divisão obrigatória das espécies de remuneração de capitais próprios e de terceiros. Conforme o modelo de Demonstrações Financeiras Padronizadas (DFP), da Comissão de Valores Mobiliários (CVM), compõe a remuneração de capitais próprios os dividendos, os JCP, lucros retidos e participação de não controladas nos lucros retidos. E no cômputo de remuneração de capitais de terceiros estão, separadamente, juros, aluguéis e outras remunerações. Diante da estrutura informacional de distribuição de riqueza evidenciada na DVA, é possível intuir que os juros presentes no cômputo de remuneração de capitais de terceiros possam ser uma variável que reportaria com mais precisão os custos de carregamento de financiamentos ante às despesas financeiras da Demonstração do Resultado.

Tendo em vista que a composição das despesas financeiras pode conter elementos que, por definição, não podem ser conceituados como itens de remuneração de capitais de terceiros e que a DVA separa a remuneração de capitais por origem, a investigação respondeu a seguinte questão de pesquisa: qual a influência do nível de disclosure voluntário sobre os juros de capital de terceiros? Consequentemente, o objetivo do estudo consiste em examinar o efeito de decisões de evidenciação voluntária sobre os custos decorrentes da aquisição de financiamentos junto a terceiros. Como justificativa socioeconômica, este estudo discute o uso de uma proxy para custos de financiamento externos diferente daquelas utilizadas em pesquisas precedentes no ambiente regulatório brasileiro. Desse modo, uma de suas contribuições foi sofisticar a investigação de fatores explicativos dos custos de endividamento junto a terceiros. 


\section{REVISÃO DE LITERATURA E DESENVOLVIMENTO DA HIPÓTESE}

A divulgação corporativa representa, segundo Gibbins, Richardson e Waterhouse (1990), o conjunto de informações contábeis de natureza qualitativa e quantitativa transmitida ao mercado de capitais por meio de canais formais e informais. Esses canais servem para conduzir as informações sobre o desempenho subjacente das empresas aos diversos usuários das informações contábeis. Yamamoto e Salotti (2006) aduzem que é coerente afirmar que o conteúdo levado ao mercado pode exercer influência sobre o comportamento tanto de investidores e credores, quanto de quem as divulga.

A divulgação voluntária representa a propensão de os gestores liberarem informação adicional ao mercado, ou seja, de ir além do que é requerido por norma ou lei (DEPOERS, 2000). Murcia e Santos (2012) defendem que o disclosure se fundamenta na lógica de que, caso a informação não fosse divulgada, a decisão do usuário seria diferente. Assim, o disclosure seria capaz de permitir não somente a avaliação da situação patrimonial, mas também auxiliar na realização de inferências sobre desempenho futuro da companhia. A partir deste enfoque e tendo em vista a possibilidade de mudança de postura do usuário frente à informação divulgada, pode-se inferir que políticas de divulgação se propagam sobre a percepção de risco por parte do usuário em relação ao futuro da empresa.

Quando as empresas optam por níveis mais elevados de divulgação de informações permitem aos investidores melhor avaliar o risco envolvido nas operações, ao passo que está em aberto o debate quanto ao risco de assimetria de informação associada a fatores idiossincráticos ser diversificável ou não (BOTOSAN, 2006; EASLEY; O'HARA, 2004, HUGHES; LIU, 2007). O benefício para a empresa decorrente do provimento de informações reflete em um menor custo de capital próprio e um menor custo do capital de terceiros. Bertomeu, Beyer e Dye (2011) apresentam um modelo para explicar conjuntamente a política de divulgação voluntária, estrutura de capital e o custo de capital das empresas e, demonstram existir uma interdependência entre divulgação voluntária e estrutura de capital, a qual determina o custo de capital da empresa. Sob o ponto de vista do custo do capital próprio, a relação negativa sugere que o nível de disclosure voluntário crescente tende a tornar projetos de investimentos, antes inaceitáveis ou críticos, viáveis por produzirem riqueza em volume financeiro que excede os investimentos iniciais (LOPES; ALENCAR, 2010). Em relação aos juros arcados para obtenção de recursos junto a terceiros para financiamentos de projetos de investimento, a adoção de práticas de evidenciação, além da regulação governamental, pode resultar em maior poder de barganha da firma aumentando a possibilidade de aquisições de fontes de financiamento relativamente menos onerosas (LIMA, 2009).

Sengupta (1998), motivado em investigar a ligação entre as decisões tomadas sobre o que evidenciar e o que não evidenciar ao mercado de capitais, observou regularidades suficientes para afirmar que níveis mais elevados de divulgação voluntária estão relacionados ao acesso a fontes empréstimos menos onerosas. Tais evidências influenciaram pesquisas de temática semelhante porque mostraram que credores interpretam políticas de disclosure voluntário como relevante para a avaliação do risco de crédito. Na mesma direção, Salotti e Yamamoto (2008) ressaltam que fornecedores de recursos tendem a manter confiança em empresas com elevado nível de disclosure mesmo em momentos de incerteza.

Sob o pressuposto de que a divulgação voluntária consistente e oportuna viabiliza o acesso das empresas às fontes de financiamento com menores custos de capital próprio e de terceiros, Mazumdar e Sengupta (2005) investigaram a influência da qualidade da divulgação global sobre o ônus do financiamento bancário e, constataram que a dispobilização

Revista Ambiente Contábil - ISSN 2176-9036 - UFRN - Natal-RN. v. 9. n. 2, p. 334 - 354, jul./dez. 2017. 
sistemática ao mercado de informações tempestivas e detalhada pelas empresas reduz o spreads de empréstimos bancários. Nessa mesma linha, mas considerando as manifestações sobre a condução de políticas de meio ambiente na China, Xuan, Zhang e Song (2014) investigaram os possíveis efeitos de políticas de disclosure voluntário ambiental sobre custos de aquisição de empréstimos e observaram que, quanto maior a divulgação voluntária menor o custo de captação.

A divulgação voluntária e o custo de capital estão propensos a sofrer influências do ambiente institucional e regulatório, do desenvolvimento do mercado de capitais e dos conflitos de agência prevalecentes (BALL, 2006; SHLEIFER; VISHNY, 1997; SILVEIRA; PEROBELLI; BARROS, 2008; MURCIA; SANTOS, 2009; LOPES; ALENCAR, 2010; MARTINS; TERRA, 2015). Considerando a possibilidade de interação entre a divulgação voluntária e a divulgação compulsória, Consoni e Colauto (2016) constataram que durante o processo de convergência às Normas Internacionais de Contabilidade no Brasil as empresas aumentaram, em média, a divulgação voluntária de informações econômicas e financeiras em termos de presença e detalhamento do conteúdo informacional. Além do efeito do processo de convergência, o porte da empresa, a liquidez das ações, a adesão aos níveis diferenciados de governança corporativa da BM\&FBovespa e a regulação setorial apresentaram relação positiva e significativa com a divulgação voluntária.

Em relação ao custo do capital de terceiros, Lima (2009) constatou existir relação inversa e significativa entre divulgação voluntária e custo do capital de terceiros em empresas brasileiras de capital aberto no período de 2000 a 2004. Nesse estudo, aproximadamente $28 \%$ da variação do custo da dívida foi explicado pela variação do índice global de divulgação voluntária de informações econômicas e ambientais das empresas brasileiras e demais variáveis independentes.

No entanto, para mensurar o ônus de manutenção de fontes de financiamentos externos, Lima (2009) utilizou como medida a despesa com juros reportada na Demonstração do Resultado, o que pode representar um problema já que a composição dessa rubrica abarca componentes de remuneração de capital próprio. No Brasil, a Lei 9.249/95 (BRASIL, 1995) criou a possibilidade de empresas brasileiras remunerarem acionistas de forma alternativa ao pagamento de dividendos, utilizando-se dos JCP. Diferente dos dividendos, os JCP são considerados despesas operacionais dedutíveis para fins de apuração de imposto de renda e têm caráter opcional. Segundo a legislação brasileira, os JCP são condicionados a existência de lucro e são contabilizados como despesas financeiras. Como alternativa à consecução do objetivo proposto, utiliza-se do valor declarado na rubrica de remuneração do capital de terceiros advindo da DVA. Portanto, a discussão anterior permite estabelecer a seguinte hipótese de pesquisa:

\section{H1: A divulgação voluntária influencia negativamente a remuneração de capitais de terceiros na forma de juros.}

\section{PROCEDIMENTOS METODOLÓGICOS}

Esta pesquisa examina o efeito de decisões de disclosure voluntário sobre o custo da dívida de financiamentos de curto e longo prazos em empresas listadas na BM\&FBOVESPA. A seguir são apresentadas as variáveis de pesquisa, o modelo econométrico que examina a influência do disclosure voluntário sobre o custo da dívida e o teste de hipóteses que conduzirá ao exame da hipótese teórica proposta. 
Os procedimentos necessários para a coleta de informações voluntárias das empresas influenciaram a definição da amostra, uma vez que exige intenso trabalho manual. Trata-se de um estudo empírico que tem como amostra final 57 empresas brasileiras listadas nos anos de 2010, 2011 e 2012. A amostra é caracteriza pela presença do viés de sobrevivência, uma vez que apenas empresas com registro ativo em bolsa foram consideradas e, consequentemente, não permite generalizações. Embora esta limitação esteja presente e torne a amostra como sendo não probabilística, acredita-se que o critério adotado não seja um empecilho de condução da pesquisa.

\subsection{DEFINIÇÃO DAS VARIÁVEIS DE PESQUISA}

Neste subitem são apresentadas as definições constitutivas e operacionais da variável dependente representada pelos juros de financiamentos e definida como custo da dívida. Além disso, é delineada a variável utilizada para mensurar o disclosure voluntário e as demais variáveis independentes que exercem a função de controle.

\subsubsection{CUSTO DA DÍVIDA (Ke)}

Os juros de financiamento, variável dependente $\left(\mathrm{K}_{\mathrm{e}}\right)$, referem-se ao constructo intitulado remuneração de capitais de terceiros. Este constructo pode ser observado na estrutura codificada das Demonstrações Contábeis Padronizadas (DFP) que as empresas brasileiras são obrigadas a reportar à Comissão de Valores Mobiliários (CVM) periodicamente. No constructo da Remuneração de Capitais de Terceiros (7.08.03) constam as variáveis Juros de Financiamentos (7.08.03.01), Aluguéis (7.08.03.02) e Outras Remunerações (7.08.03.03). Tendo em vista que os juros presentes na remuneração de capitais de terceiros incluem variações cambiais passivas relativas a empréstimos e financiamentos, a proxy utilizada para mensuração do custo da dívida foi obtida por meio da diferença entre o valor total da Remuneração de Capital de Terceiros e o valor dos Aluguéis. Em seguida, o valor resultante foi divido pela soma do saldo de empréstimos e financiamentos mantidos, perfazendo a proporção de custo de dívida em relação ao total do passivo oneroso.

\subsection{2 ÍNDICE DE DISCLOSURE VOLUNTÁRIO (IDV)}

Para a caracterização da variável independente, divulgação voluntária das empresas, foi utilizado o Índice de Divulgação Voluntária (IDV) proposto por Consoni e Colauto (2016). O conteúdo desse índice refere-se às informações econômicas e financeiras (Quadro 1). A métrica foi elaborada considerando apenas os elementos que mantiveram sua natureza voluntária após o período de convergência às Normas Internacionais de Contabilidade no Brasil.

\section{Quadro 1: Conteúdo do Índice de Divulgação Voluntária (IDV)}

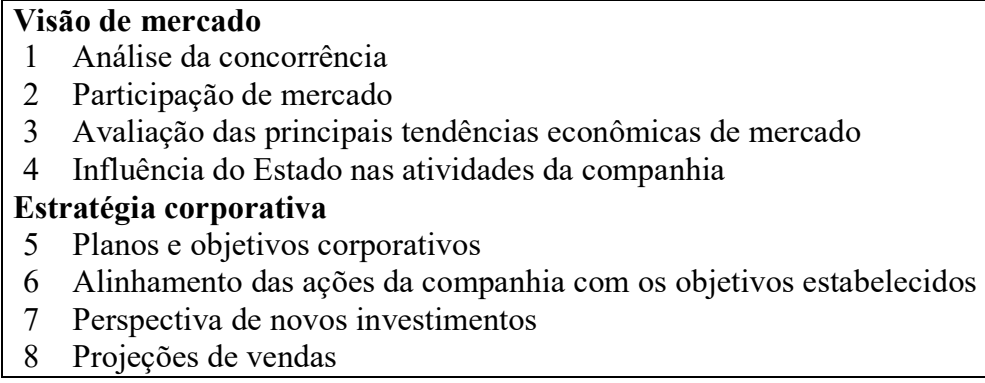

Revista Ambiente Contábil - ISSN 2176-9036 - UFRN - Natal-RN. v. 9. n. 2, p. 334 - 354, jul./dez. 2017. 
9 Projeções de lucros

10 Projeções de fluxos de caixa

Desempenho econômico-financeiro

11 Variação dos estoques de mercadorias para venda, de insumos ou de produtos acabados

12 Variação dos recebíveis

13 Variação do volume das vendas

14 Variação das despesas administrativas e comerciais

15 Variação do resultado operacional

16 Variação dos custos das mercadorias vendidas, dos produtos fabricados ou serviços prestados

17 Efeito financeiro proveniente da captação de recursos de terceiros de curto e longo prazo

18 Efeito financeiro proveniente da aplicação de recursos próprios

19 Comportamento do valor das ações ordinárias e preferenciais

20 Indicadores globais (EVA, EBITDA, MVA)

21 Custo de capital próprio

Aspectos operacionais

22 Produção corrente em relação à capacidade instalada

23 Medidas de eficiência operacional

24 Dependência de tecnologia, de fornecedores, de clientes ou de mão de obra

25 Investimentos/desinvestimentos realizados

26 Recursos investidos em gestão do capital humano

27 Recursos investidos em projetos de educação, cultura e desenvolvimento social

Fonte: Adaptado de Consoni e Colauto (2016).

As informações necessárias para elaboração do nível de disclosure voluntário foram extraídas dos Relatórios de Administração, dos Formulários de Informações Anuais (IAN) e dos Formulários de Referência presentes no website da CVM.

Para cada um dos 27 itens que integraram as 4 dimensões do instrumento de coleta de informações, utilizou-se um roteiro de análise para examinar a pertinência entre o enunciado do item presente no instrumento e os fragmentos textuais presentes nos relatórios consultados para cada empresa-ano. O procedimento de codificação foi o mesmo adotado por Consoni e Colauto (2016). Dessa forma, foram estabelecidos três critérios de codificação possíveis: Informação ausente: 0 (zero) ponto quando nenhuma informação é apresentada sobre o item em análise; Informação declarativa: 1 (um) ponto quando somente a informação qualitativa é apresentada e expressa em termos puramente descritivos; Informação declarativa $e$ quantitativa (monetária e não-monetária): 2 (dois) pontos se a informação é apresentada de forma declarativa e expressa em números de natureza financeira e não-financeira.

Acredita-se que esta forma de codificação não prejudica a mensuração da variável, pois o conteúdo a ser divulgado na forma descritiva é passível de ser mensurado quantitativamente e, assim, explorar particularidades de divulgação das empresas. Este critério de codificação possibilita a cada empresa obter uma pontuação máxima de 54 pontos. Portanto, o índice de divulgação voluntária foi obtido pela divisão da pontuação máxima pela pontuação obtida pela empresa, apresentando um indicador que varia de 0 a 1.

\subsubsection{VARIÁVEIS DE CONTROLE}

Como variáveis de controle utilizou-se o Tamanho, a Alavancagem financeira e o Valor de Mercado das empresas da amostra. O objetivo da utilização dessas variáveis de controle foi o exame da direção da regularidade dos seus desempenhos em relação ao custo da dívida. Os sinais esperados para as variáveis de controle, suas definições operacionais e referências estão descritas no Quadro 2. 
Quadro 2: Variáveis de controle da pesquisa

\begin{tabular}{|c|c|c|c|c|}
\hline Variável & Sigla & $\begin{array}{r}\text { Relação } \\
\text { esperada }\end{array}$ & Forma de Cálculo & Referências \\
\hline Tamanho & $\mathrm{TAM}_{\mathrm{it}}$ & - & $\begin{array}{l}\text { Logaritmo natural das } \\
\text { eceitas }\end{array}$ & $\begin{array}{l}\text { ANDERSON; MANSI; } \\
\text { REEB (2003, 2004), } \\
\text { PITTMAN; FORTIN } \\
\text { (2004), FRANCIS; } \\
\text { KHURANA; PEREIRA } \\
(2005), \text { LIMA (2009). }\end{array}$ \\
\hline Alavancagem Financeira & $\mathrm{ALAV}_{\text {it }}$ & + & $\begin{array}{l}\text { Razão do total de dívidas } \\
\text { no período t e o ativo total } \\
\text { em t-1 }\end{array}$ & $\begin{array}{l}\text { ANDERSON; MANSI; } \\
\text { REEB (2003, 2004), } \\
\text { PITTMAN; FORTIN } \\
\text { (2004), AHMED; } \\
\text { BILLING; MORTON; } \\
\text { STANFORD (2002), LIMA } \\
\text { (2009), CHEN (2012) }\end{array}$ \\
\hline $\begin{array}{l}\text { Valor de Mercado da } \\
\text { Empresa }\end{array}$ & $\mathrm{MKV}_{\text {it }}$ & - & $\begin{array}{l}\text { Valor médio das ações e as } \\
\text { quantidades. Razão deste } \\
\text { valor e ativos totais em t-1 }\end{array}$ & LIMA (2009) \\
\hline
\end{tabular}

Fonte: Elaborado pelos autores

\subsection{MÉTODO ESTATÍSTICO}

O exame dos dados da presente pesquisa ocorre por meio da análise exploratória de dados e Regressão Linear Múltipla com Dados em Painel. Embora a análise exploratória de dados não tenha a função de examinar a relação entre as variáveis de pesquisa, auxilia na avaliação dos dados. Levine et al. (2005) observa que métricas como desvio-padrão e média, por exemplo, podem apresentar indícios da presença de informações atípicas em determinadas variáveis. Tais informações influentes (ou outliers) podem ter efeito suficiente para modificar a interpretação do evento em investigação.

A computação da análise de Regressão Linear Múltipla tem o objetivo de observar a influência do Índice de Disclosure Voluntário (IDV) sobre o custo da dívida medido a partir dos juros sobre financiamentos. Segundo Wooldridge (2006), as estruturas típicas para aplicação da Regressão Linear Múltipla são organizadas em cortes transversais (diversas unidades de observação em um período), séries temporais (uma unidade de observação em mais de um período) e dados em painel (mais de uma unidade de observação em mais de um período). $\mathrm{O}$ emprego da abordagem de dados em painel para a análise da influência de que trata este estudo decorre do fato de ter-se examinando determinada amostra de empresas em uma série especifica de tempo. O método de estimação do coeficiente associado ao IDV será o método de Mínimos Quadrados Ordinários (MQO). Levando em conta a possibilidade de observação de indícios de informações influentes (outliers), aplicou-se a análise de distâncias de Mahalanobis. A aplicação deste exame teve o objetivo de verificar se, caso sejam excluídos os casos atípicos, os coeficientes da regressão se manteriam apontando para a mesma direção e com o mesmo nível de significância anterior (FIELD, 2009). A verificação das distâncias de Mahalanobis pode ser vista como útil para deteç̧ão de outilers multivariados (HAIR et al., 2005). 


\subsection{MODELO ECONOMÉTRICO}

O modelo econométrico a ser utilizado tem como variável dependente o custo da dívida $\left(K_{e}\right)$ e como independentes o Índice de Disclosure Voluntário (IDV), o tamanho da empresa, o nível de alavancagem financeira e o valor de mercado da companhia, conforme apresentado na Equação 1:

$$
K_{\text {eit }}=\gamma_{1}+\gamma_{2} I D V_{2 i t}+\gamma_{3} A L A V_{3 i t}+\gamma_{4} T A M_{4 i t}+\gamma_{5} M K T_{5 i t}+\varepsilon_{i t}
$$

Em que:

$I D V_{i t}$ indica o Índice de Disclosure Voluntário

$A L A V_{i t}$ é a alavancagem financeira

$T A M_{i t}$ indica o porte da empresa

$M K T_{i t}$ indica o valor de mercado

Os parâmetros descritos por gama $(\gamma)$ são os coeficientes a serem estimados. É a partir dos sinais obtidos e da significância estatística associada às estimações desses parâmetros que a hipótese de influência do IDV será examinada. A partir da contextualização do trabalho, evidências precedentes e da fundamentação apresentadas em seções anteriores, espera-se que as práticas de disclosure voluntário exerçam efeito negativo e significativo ao nível de 5\%.

\subsection{HIPÓTESE DE TESTE}

Gujarati e Porter (2011) mostram que testes de hipóteses ligados a estimação de parâmetros de um modelo de Regressão Linear Múltipla podem ser unicaudais (ou unilaterais) à esquerda ou à direita indicando a direção do teste de hipótese que guiará o exame dos resultados do estudo. Como teste de hipótese, espera-se sinal negativo para o coeficiente $\gamma_{2} \mathrm{e}$, portanto, trata-se de um teste unicaudal à esquerda, tendo-se como hipóteses nula e alternativa as seguintes identidades:

$$
\begin{aligned}
& \mathrm{H}_{0}: \gamma_{2} \geq 0 \\
& \mathrm{H}_{1}: \gamma_{2}<0
\end{aligned}
$$

Deve-se observar que durante a computação da regressão foram realizados testes de hipóteses ligados ao desempenho do intercepto da Equação 1. Inicialmente, testou-se a hipótese de o modelo ser POLS (Pooled Ordinary Least Squares). Em seguida foi aplicado o Teste de Chow para verificação da presença de efeitos fixos. E, finalmente, foi examinada a hipótese de se tratar de um modelo com efeitos aleatórios (ADKINS, 2014). 


\section{ANÁLISE DOS RESULTADOS}

Na Tabela 1 apresenta-se a estatística descritiva da base de dados, além da frequência de observações abaixo de 3 desvios-padrão e acima de 3 desvios-padrão para sinalizar a presença de observações influentes.

Tabela 1: Estatísticas descritivas das variáveis para a amostra da pesquisa

\begin{tabular}{l|c|c|c|c|c}
\hline Descrição & Ke & IDV & ALAV & TAM & MKV \\
\hline Máximo & 6,984 & 0,833 & 1,996 & 24,960 & 6,988 \\
\hline Mínimo & 0,002 & 0,074 & 0,016 & 16,615 & 0,549 \\
\hline Média & 0,293 & 0,490 & 0,360 & 21,898 & 1,525 \\
\hline Desvio Padrão & 0,712 & 0,157 & 0,234 & 1,841 & 0,988 \\
\hline Coeficiente de Variação & $243,27 \%$ & $32,03 \%$ & $64,97 \%$ & $8,41 \%$ & $64,78 \%$ \\
\hline Score Z<-3ou > 3 desv. & 3 & 0 & 3 & 0 & 6 \\
\hline
\end{tabular}

Nota. $K_{\mathrm{e}}$ : custo da dívida; IDV: Índice de Disclosure Voluntário; ALAV: Alavancagem financeira; TAM:

Tamanho da empresa (logaritmo natural do ativo); MKV: Valor de mercado da companhia.

Fonte: Dados da pesquisa

Observa-se que a variável de maior dispersão é o custo da dívida $\left(K_{e}\right)$ seguida do valor de mercado (MKV) e da alavancagem financeira (ALAV) com 243,27\%, 64,97\% e 64,78\% de coeficiente de variação, respectivamente. Embora a análise descritiva de dados não mostre como se configuram as diferenças entre as variáveis, o Índice de Disclosure Voluntário (IDV) apresenta dispersão suficiente para se observar que há diferenças de níveis de Disclosure entre as empresas da amostra. Portanto, como ponto de partida, tem-se que as empresas se diferenciam entre si em termos de políticas de evidenciação voluntária.

Apesar da Tabela 1 não discriminar o nível desta diferença, pode-se observar que há empresas com escores de disclosure voluntário acima de $80 \%$ e também aquelas com ausência quase total de informações declarativas que permitissem avaliá-las. Dentre as variáveis de pesquisa, o custo da dívida $\left(K_{e}\right)$ apresenta grande dispersão tendo em vista que, em relação à média, o desvio padrão dessa variável é o maior se comparado às demais, indicando que as diferenças entre taxas de juros de financiamento das empresas é a variável de maior dispersão relativa.

Na linha Score $Z<-3$ ou $>3$ da Tabela 1 , há 12 observações extraordinárias, sendo 3 na variável custo da dívida $\left(K_{e}\right), 3$ na alavancagem (ALAV) e 6 no valor de mercado (MKV). Essas frequências de observações atípicas não se concentram nas mesmas empresas ao longo da amostra. Para a variável $K_{e}$, as três observações descritas se referem à empresa Whrilpool S/A do segmento de móveis para residência. Para a variável alavancagem, as três observações se concentram na companhia Haga S/A do ramo de materiais para construção. Também fora do intervalo de 3 desvios-padrão, são observados dois casos para a empresa Haga S/A (anos de 2010 e 2011), três casos para a empresa Natura e dois casos para a empresa Ambev (ano de 2012).

As 12 observações atípicas da amostra podem influenciar o desempenho das estimações dos parâmetros das variáveis independentes tendo em vista que podem alavancar a determinação dos estimadores. O possível efeito da presença de alavancagem sobre as variáveis de pesquisa é a condução a conclusões desarmônicas sobre a associação entre as

Revista Ambiente Contábil - ISSN 2176-9036 - UFRN - Natal-RN. v. 9. n. 2, p. 334 - 354, jul./dez. 2017. 
variáveis pesquisadas e por esse motivo os exames e interpretações apresentados adiante consideraram a presença e a ausência de informações atípicas sobre os resultados analisados.

$\mathrm{Na}$ Tabela 2 são apresentas as relações entre as variáveis por meio do coeficiente de correlação de Pearson. Essa Tabela já pode indicar, preliminarmente, a direção de associação entre as variáveis de pesquisa associado a níveis de significância de $1 \%, 5 \%$ ou $10 \%$.

\begin{tabular}{|c|c|c|c|c|c|c|}
\hline & & $\mathbf{K}_{\mathbf{e}}$ & IDV & ALAV & TAM & MKV \\
\hline \multirow[t]{2}{*}{$\mathbf{K e}$} & Coef. & 1 & & & & \\
\hline & Sig & - & & & & \\
\hline \multirow[t]{2}{*}{ IDV } & Coef. &,$- 290^{* * *}$ & 1 & & & \\
\hline & Sig & 0,001 & - & & & \\
\hline \multirow[t]{2}{*}{ ALAV } & Coef. &,$- 271^{* * *}$ & $-0,054$ & 1 & & \\
\hline & Sig & 0,000 & 0,482 & - & & \\
\hline \multirow[t]{2}{*}{ TAM } & Coef. & 0,018 & $440^{* * * *}$ &,$- 240^{* * *}$ & 1 & \\
\hline & Sig & 0,817 & 0,000 & 0,002 & - & \\
\hline \multirow[t]{2}{*}{ MKV } & Coef. & 0,008 &, 077 &,$- 255^{* *}$ &,- 038 & 1 \\
\hline & Sig & 0,922 & 0,315 & 0,001 & 0,623 & - \\
\hline \multicolumn{7}{|c|}{$\begin{array}{l}\text { Nota. } \mathrm{K}_{\mathrm{e}} \text { : custo da dívida; IDV: Índice de Disclosure Voluntário; ALAV: } \\
\text { Alavancagem financeira; TAM: Tamanho da empresa (logaritmo natural do } \\
\text { ativo); MKV: Valor de mercado da companhia. *,** } \mathrm{e}^{* * *} \text { significativos em } \\
10 \%, 5 \% \text { e } 1 \% \text {. }\end{array}$} \\
\hline
\end{tabular}

Observa-se que a variável custo de dívida $\left(\mathrm{K}_{\mathrm{e}}\right)$ se relaciona em direção oposta, conforme o previsto, com o Índice de Disclosure Voluntário (IDV). Ao nível de significância de $1 \%$, tem-se que níveis mais elevados de disclosure voluntário estão associados a percentuais mais baixos de custos de financiamentos. Embora essa relação empírica apresente indícios favoráveis à hipótese teórica e a hipótese de teste da pesquisa, deve-se ater ao fato de que a amostra apresenta observações atípicas, as quais não só podem influenciar o resultado como também modificar a direção de associação entre as variáveis.

Nota-se ainda na Tabela 2 que as variáveis de controle consideradas no modelo apresentaram comportamentos distintos. A Alavancagem comporta-se de forma muito similar ao disclosure voluntário, tanto na significância do coeficiente quanto no sinal do mesmo. Já o tamanho da empresa e seu valor de mercado não indicam nenhuma relação com o custo da dívida das empresas, demonstrando que essa variável não é influenciada nem pelo porte da empresa e nem por sua valorização no mercado.

A análise multivariada foi realizada a partir da Equação 1 anteriormente descrita. $\mathrm{Na}$ Tabela 3 são apresentadas as estimações dos coeficientes da Regressão Linear Múltipla considerando-se três Modelos. No Modelo 1, a Regressão Linear Múltipla é computada considerando a totalidade dos dados das 57 empresas da amostra nos anos de 2010, 2011 e 2012. Tendo em vista que a distância de Mahalanobis para $k$ variáveis independentes segue uma distribuição qui-quadrado com $k$ - 1 graus de liberdade, no Modelo 2 foram consideradas atípicas aquelas observações que apresentaram qui-quadrado calculado acima do valor crítico de 11,34. Para esse Modelo foram considerados 3 graus de liberdade para significância estatística de $1 \%$. As observações que ultrapassaram o valor crítico foram retiradas e então novamente os regressores foram estimados. E, finalmente, no Modelo 3 a estimação dos coeficientes foi examinada por meio da exclusão das observações atípicas com significância de 5\%,3 graus de liberdade e com o valor crítico do qui-quadrado 7,81. Estes valores críticos exercem a função de valor de corte para análise de presença de valores atípicos. A terceira

Revista Ambiente Contábil - ISSN 2176-9036 - UFRN - Natal-RN. v. 9. n. 2, p. 334 - 354, jul./dez. 2017. 
abordagem se mostra como a mais rigorosa para examinar da influência de casos atípicos sobre a relação entre custo da dívida e disclosure voluntário porque mostra o resultado da estimação dos parâmetros da Regressão Linear Múltipla sem a presença de informações desviantes em sua totalidade.

Tabela 3: Coeficientes estimados para a Equação 1

\begin{tabular}{lccc}
\hline Variáveis Independentes & Modelo 1 & Modelo 2 & Modelo 3 \\
\hline IDV & $-1,0693 * *$ & $-1,1250 * *$ & $-0,0447$ \\
& 0,4196 & 0,4639 & 0,1847 \\
\hline ALAV & $-0,4938^{* *}$ & $-0,6427 * *$ & $-0,2573 *$ \\
& 0,2217 & 0,3281 & 0,1490 \\
\hline TAM & 0,0395 & 0,0495 & $-0,0107$ \\
& 0,0464 & 0,0557 & 0,0187 \\
\hline MKV & $0,0949 *$ & $0,1743 *$ & $-0,0206$ \\
& 0,0639 & 0,1138 & 0,0480 \\
\hline Constante & $-0,0148$ & $-0,2495$ & 0,5676 \\
& 0,9910 & 1,1785 & 0,3879 \\
\hline Estatística de teste de Chow $(F)$ & $\mathbf{2 3 , 2 6 6 * * *}$ & $\mathbf{2 2 , 5 2 4} * * *$ & $\mathbf{1 1 , 3 1 8 * * *}$ \\
\hline Estatística de teste de Breusch-Pagan $\left(\chi^{2}\right)$ & $\mathbf{1 3 0 , 1 0 3 * * *}$ & $\mathbf{1 1 9 , 4 5 4 * * *}$ & $\mathbf{7 3 , 1 9 0 * * *}$ \\
\hline Teste de Hausman $\left(\chi^{2}\right)$ & $\mathbf{4 , 9 7 0}$ & $\mathbf{4 , 6 3 6}$ & $\mathbf{4 , 3 0 4}$ \\
\hline $\mathrm{R}^{2}$ ajustado & $15,42 \%$ & $18,25 \%$ & $9,43 \%$ \\
\hline Observações & 171 & 159 & 129 \\
\hline Nota. K $:$ us &
\end{tabular}

Nota. $\mathrm{K}_{\mathrm{e}}$ : custo da dívida; IDV: Índice de Disclosure Voluntário; ALAV: Alavancagem financeira; TAM: Tamanho da empresa (logaritmo natural do Ativo); MKV: Valor de mercado da companhia. *, ** $\mathrm{e}^{* * *}$ significativos em 10\%, 5\% e 1\%. Estatística de teste de Chow: contrariou a hipótese nula de que o modelo MQO agrupado (pooled) é adequado, validando a hipótese alternativa da existência de efeitos fixos. Estatística de teste de Breusch-Pagan: contrariou a hipótese nula de que o modelo MQO agrupado (pooled) é adequado, validando a hipótese alternativa da existência de efeitos aleatórios. Teste de Hausman: não contrariou a hipótese nula de que o modelo de efeitos aleatórios é consistente, mostrando-se tratar de estimações MQG (Mínimos Quadrados Generalizados) nos três modelos.

Fonte: Dados da pesquisa

A partir dos coeficientes estimados para as variáveis independentes do Modelo 1, observa-se influência negativa do índice de disclosure voluntário (IDV) sobre o custo da dívida. Estes resultados são semelhantes àqueles encontrados por Lima (2009), embora a proxy de custo de financiamento de terceiros seja diferente daquela utilizada na presente pesquisa. Tanto na variável Alavancagem Financeira (ALAV) quanto no Valor de Mercado (MKT), os coeficientes da regressão se mostraram significativos ao nível de 5\% e $10 \%$, no entanto com sinais divergentes aos de pesquisas internacionais precedentes. Em especifico, a variável Alavancagem Financeira apontou a mesma direção do trabalho realizado por Lima (2009), mas no caso específico do Valor de Mercado o sinal obtido foi contrário. A variável Tamanho (TAM) das empresas mostrou sinal positivo e não significativo indicado não haver relação entre o porte das companhias e o custo do carregamento de suas dívidas. As estimações obtidas a partir do Modelo 1 sugerem que práticas de evidenciação voluntária relativas a decisões empresa sobre a dinâmica do ambiente econômico, sua atuação e o desempenho obtido, propagam-se sobre o mercado de capitais e se traduzem em taxas menores de financiamentos de curto e longo prazos.

Embora inicialmente esses resultados coadunem à hipótese teórica da pesquisa, deve-se ressaltar que dentre as 171 observações que compõe o Modelo 1 foram detectadas 11 observações atípicas. Essas observações são apresentadas na Tabela 4 na coluna "MAH". 
Tabela 4: Descrição da distância de Mahalanobis para exame de outliers multivariados (valor crítico para o qui-quadrado: 11,34)

\begin{tabular}{l|l|c|c|c|c|c|c|c}
\hline \multicolumn{1}{c}{ Descrição } & \multicolumn{1}{c|}{ Setor } & Ano & IDV & $\mathbf{K}_{\mathbf{e}}$ & TAM & ALAV & MKV & MAH \\
\hline AES TIETE & Energia Elétrica & 2010 & 0,778 & 0,156 & 16,678 & 0,219 & 1,610 & 22,154 \\
\hline AES TIETE & Energia Elétrica & 2011 & 0,704 & 0,109 & 16,661 & 0,224 & 1,854 & 18,838 \\
\hline AES TIETE & Energia Elétrica & 2012 & 0,704 & 0,083 & 16,615 & 0,232 & 1,771 & 18,911 \\
\hline AMBEV AS & Alimentos e Bebidas & 2010 & 0,648 & 0,156 & 24,477 & 0,159 & 4,103 & 10,686 \\
\hline AMBEV AS & Alimentos e Bebidas & 2011 & 0,667 & 0,295 & 24,555 & 0,089 & 4,103 & 11,742 \\
\hline AMBEV AS & Alimentos e Bebidas & 2012 & 0,722 & 0,463 & 24,848 & 0,051 & 4,920 & 18,816 \\
\hline FER HAGA & Siderurgia e Metalurgia & 2010 & 0,185 & 0,015 & 17,379 & 1,996 & 5,016 & 55,327 \\
\hline FER HAGA & Siderurgia e Metalurgia & 2011 & 0,185 & 0,010 & 17,387 & 1,702 & 5,016 & 41,124 \\
\hline FER HAGA & Siderurgia e Metalurgia & 2012 & 0,185 & 0,003 & 17,497 & 1,278 & 3,870 & 21,569 \\
\hline NATURA & Cosméticos e Cuidados Pessoais & 2010 & 0,648 & 0,170 & 21,893 & 0,215 & 6,988 & 35,480 \\
\hline NATURA & Cosméticos e Cuidados Pessoais & 2011 & 0,648 & 0,178 & 22,056 & 0,313 & 6,988 & 33,692 \\
\hline NATURA & Cosméticos e Cuidados Pessoais & 2012 & 0,648 & 0,125 & 22,402 & 0,434 & 5,459 & 16,813 \\
\hline
\end{tabular}

Fonte: Dados da pesquisa

O número de observações atípicas, tendo em vista o valor de corte para o qui-quadrado de 11,34, é de 11 observações. A Tabela 4 descreve 12 observações atípicas porque em uma das empresas, duas das três observações anuais, mostraram-se como outliers multivariados (anos de 2011 e 2012 para empresa Ambev SA). Esse procedimento foi adotado porque caso fossem excluídas somente as observações influentes, a base de dados ficaria desbalanceada e apenas com uma informação da companhia Ambev. Tendo como base a descrição de dados apresentada na seção 4.1 e comparando-a a Tabela 1, vê-se que 3 das 4 empresas que apresentam escore $Z$ abaixo de -3 e acima de 3 desvios-padrão, também apresentam a distância de Mahalanobis acima do valor crítico de 11,34.

No Modelo 2, a regressão múltipla foi computada excluindo-se as 12 (doze) observações indicadas na Tabela 4, as quais apresentaram o valor calculado da distância de Mahalanobis acima do valor de corte da estatística qui-quadrado. Semelhante ao Modelo 1, os resultados do Modelo 2 preservam a influência negativa do disclosure voluntário (IDV) sobre o custo da dívida ao nível de $1 \%$. Sobre as demais variáveis não se observam modificações em relação ao Modelo 1.

O Modelo 3 foi apresentado considerando 3 graus de liberdade e 5\% de significância estatística como valor crítico para a distância de Mahalanobis. Este valor crítico é 7,81. Na Tabela 5 são mostradas as empresas cuja distância de Mahalanobis se apresentou acima desse valor crítico. Na Tabela 5, observa-se que 21 observações apresentam distâncias de Mahalanobis acima do valor crítico, o que as configura como outliers multivariados. 
Tabela 5: Descrição da distância de Mahalanobis para exame de outliers multivariados (valor crítico para o qui-quadrado: 7,81 )

\begin{tabular}{|c|c|c|c|c|c|c|c|c|}
\hline Descrição & Setor & Ano & IDV & $\mathbf{K}_{\mathbf{e}}$ & TAM & ALAV & MKV & МАН \\
\hline ALPARGATAS & Têxtil & 2010 & 0,500 & 0,133 & 21,533 & 0,132 & 2,090 & 6,246 \\
\hline ALPARGATAS & Têxtil & 2011 & 0,481 & 0,368 & 21,602 & 0,098 & 2,090 & 6,716 \\
\hline ALPARGATAS & Têxtil & 2012 & 0,500 & 0,332 & 21,731 & 0,109 & 2,507 & 11,144 \\
\hline EMBRATEL & Telecomunicações & 2010 & 0,259 & 0,076 & 23,747 & 0,254 & 1,011 & 7,715 \\
\hline EMBRATEL & Telecomunicações & 2011 & 0,259 & 0,130 & 23,796 & 0,158 & 1,011 & 7,956 \\
\hline EMBRATEL & Telecomunicações & 2012 & 0,259 & 0,531 & 24,087 & 0,073 & 1,074 & 9,485 \\
\hline ETERNIT & Minerais não Metálicos & 2010 & 0,593 & 0,941 & 20,309 & 0,036 & 2,000 & 13,823 \\
\hline ETERNIT & Minerais não Metálicos & 2011 & 0,574 & 0,584 & 20,355 & 0,070 & 2,000 & 11,746 \\
\hline ETERNIT & Minerais não Metálicos & 2012 & 0,611 & 0,451 & 20,513 & 0,099 & 1,303 & 8,677 \\
\hline EXCELSIOR ALIMEN & Alimentação & 2010 & 0,093 & 0,268 & 17,232 & 0,349 & 1,400 & 11,023 \\
\hline EXCELSIOR ALIMEN & Alimentação & 2011 & 0,074 & 0,198 & 17,455 & 0,311 & 1,400 & 10,659 \\
\hline EXCELSIOR ALIMEN & Alimentação & 2012 & 0,130 & 0,307 & 17,495 & 0,193 & 1,366 & 9,653 \\
\hline IGUACU CAFÉ & Alimentos e Bebidas & 2010 & 0,315 & 0,054 & 20,113 & 0,561 & 0,959 & 5,445 \\
\hline IGUACU CAFÉ & Alimentos e Bebidas & 2011 & 0,333 & 0,078 & 20,295 & 0,761 & 0,959 & 11,920 \\
\hline IGUACU CAFÉ & Alimentos e Bebidas & 2012 & 0,296 & 0,593 & 20,050 & 0,343 & 1,517 & 2,482 \\
\hline LOJAS AMERIC & Varejo & 2010 & 0,481 & 0,232 & 22,802 & 0,518 & 2,342 & 7,742 \\
\hline LOJAS AMERIC & Varejo & 2011 & 0,481 & 0,217 & 22,970 & 0,528 & 2,342 & 8,109 \\
\hline LOJAS AMERIC & Varejo & 2012 & 0,481 & 0,176 & 23,128 & 0,564 & 2,491 & 10,865 \\
\hline MELHOR SP & Papel e Celulose & 2010 & 0,241 & 0,344 & 20,836 & 0,016 & 0,619 & 8,154 \\
\hline MELHOR SP & Papel e Celulose & 2011 & 0,241 & 0,494 & 21,141 & 0,018 & 0,619 & 8,141 \\
\hline MELHOR SP & Papel e Celulose & 2012 & 0,241 & 0,234 & 21,131 & 0,030 & 0,549 & 8,397 \\
\hline SID NACIONAL & Siderurgia e Metalurgia & 2010 & 0,741 & 0,089 & 24,356 & 0,531 & 1,827 & 5,258 \\
\hline SID NACIONAL & Siderurgia e Metalurgia & 2011 & 0,519 & 0,173 & 24,571 & 0,595 & 1,827 & 8,158 \\
\hline SID NACIONAL & Siderurgia e Metalurgia & 2012 & 0,519 & 0,114 & 24,699 & 0,550 & 1,163 & 6,590 \\
\hline VULCABRAS AZALEI & Têxtil & 2010 & 0,463 & 0,128 & 21,201 & 0,464 & 1,909 & 3,032 \\
\hline VULCABRAS AZALEI & Têxtil & 2011 & 0,426 & 0,263 & 21,159 & 0,690 & 1,909 & 8,655 \\
\hline VULCABRAS AZALEI & Têxtil & 2012 & 0,426 & 0,316 & 21,042 & 0,753 & 1,224 & 8,983 \\
\hline WHIRLPOOL AS & Eletrônicos & 2010 & 0,204 & 4,602 & 22,303 & 0,021 & 1,741 & 8,241 \\
\hline WHIRLPOOL AS & Eletrônicos & 2011 & 0,130 & 6,984 & 22,383 & 0,016 & 1,741 & 10,911 \\
\hline WHIRLPOOL AS & Eletrônicos & 2012 & 0,130 & 4,225 & 22,510 & 0,019 & 1,458 & 10,284 \\
\hline
\end{tabular}

Fonte: Dados da pesquisa

Com base nos dados da Tabela 5 e com base no Modelo 3, observa-se a não significância dos coeficientes das variáveis preditoras Índice de Disclosure Voluntário (IDV), tamanho da empresa (TAM) e valor de mercado (MKV). A exceção ficou para a variável Alavancagem financeira (ALAV) que manteve sinal negativo e estatisticamente significativo ao nível de e 5\% e 10\% nos Modelos 1, 2 e 3. Estes resultados sugerem duas interpretações: (1) que o custo da dívida, medido por meio dos gastos com financiamentos, não se apresenta monotonicamente distribuído ao longo da amostra. A distribuição dos dados indica, para a presente amostra, não ser possível afirmar que níveis mais elevados de disclosure voluntário estejam ligados à capacidade da empresa em obter empréstimos a custos mais baixos se comparadas às empresas com disclosure mais limitado; e (2) forte influência de 8 empresas sobre a média de comportamento de toda a amostra. A considerar a amostra de 59 empresas, tem-se resultado diametralmente oposto daquele obtido após a exclusão das 8 empresas que apresentam observações influentes.

Portanto, diante da não significância obtida para o coeficiente da regressão múltipla para a variável IDV, aceita-se a hipótese nula de que o coeficiente não difere significativamente de zero. Consequentemente, a hipótese teórica de que níveis mais elevados de disclosure estão associados a níveis mais baixos de custo de carregamento de financiamentos não pôde ser empiricamente constatada. 


\section{CONSIDERAÇÕES FINAIS}

Tendo em vista a variedade de determinantes para custo de aquisição de financiamentos, uma das preocupações que tem estimulado pesquisas é o poder da evidenciação espontânea de informações empresariais influenciarem as taxas de juros desses financiamentos. No Brasil, e em outros mercados, essa associação já foi investigada a partir de diferentes variáveis utilizadas para representar o disclosure voluntário e o custo da dívida (SENGUPTA, 1998; LIMA, 2009). A principal motivação para revisitar este tema é que a variável contábil despesas financeiras, comumente utilizada como proxy para endividamento junto a terceiros, pode conter viés de superavaliação. Esse viés se justifica pelo fato de que no Brasil as despesas com juros sobre capital próprio compõem as despesas financeiras e, portanto, estas podem não representar adequadamente o custo com juros. Como alternativa a essa limitação, utilizou-se a remuneração de capital de terceiros presentes na (DVA) cuja elaboração é obrigatória para empresas listadas desde o ano de 2008.

Este trabalho examinou para uma amostra de empresas brasileiras listadas na BM\&FBOVESPA, o efeito da divulgação voluntária sobre o custo de financiamentos. A ideia que sustenta a relação entre disclosure voluntário e custo da dívida é que aspectos qualitativos e quantitativos associados à seleção de políticas de divulgação de informações, por meio de canais formais, podem influenciar o spread de financiamentos junto ao mercado de capitais. Desse modo, empresas com nível mais elevado de evidenciação espontânea relacionada à percepção da administração sobre a dinâmica do ambiente econômico, riscos do negócio e desempenho operacional, poderiam influenciar o comportamento de fornecedores de recursos por meio da obtenção de taxas de juros de financiamento proporcionalmente menores. Diante disso, e na mesma direção de pesquisas prévias, foi formulada hipótese de relação negativa entre essas variáveis.

Em princípio, esperava-se que a condução espontânea de evidenciação sobre políticas empresariais fosse capaz de prover conteúdo suficiente para possibilitar a diminuição do ônus na aquisição de financiamentos. No entanto, para os dados disponíveis das empresas amostradas e partir do tratamento estatístico utilizado nesta pesquisa, constatou-se que o nível de disclosure voluntário não influencia negativamente a magnitude da taxa de juros de financiamentos. Sob o ponto de vista da descrição dos dados, as empresas que compõe a amostra são diferentes em seus níveis de evidenciação voluntária e também diferentes em termos de spreads de financiamentos adquiridos. No entanto, a análise de inferência utilizada não revelou associação entre estes níveis. $\mathrm{O}$ exame dos dados sugere que modificações realizadas em práticas de evidenciação voluntária não transmitem informação ao mercado de capitais em magnitude suficiente para alterar o comportamento de agentes econômicos fornecedores de recursos.

Os indícios de que o Índice de Disclosure Voluntário (IDV) não é capaz de diferenciar as empresas em termos de custos de financiamentos contraria a hipótese teórica estabelecida e as evidências dos achados de Lima (2009). Há pelo menos duas explicações possíveis para isso, as quais sugerem cautela ao analisar os resultados deste trabalho. A primeira está ligada a proxy usada para o custo da dívida. O interregno de tempo utilizado nos estudos de Lima (2009) foram os anos 2000 a 2004. Nesse período a DVA não era de divulgação obrigatória e portanto, havia limitações para a identificação de uma variável mais precisa que as despesas financeiras para mensurar o custo da dívida. A outra explicação é que, embora parte do instrumento de pesquisa desenvolvido por Consoni e Colauto (2016) se baseie em índices propsotos e aplicados no contexto brasileiro por outros pesquisadores, trata-se de um

Revista Ambiente Contábil - ISSN 2176-9036 - UFRN - Natal-RN. v. 9. n. 2, p. 334 - 354, jul./dez. 2017. 
instrumento construído a partir de um conjunto de escolhas. Assim, o conjunto de itens selecionados para compor o IDV pode não descrever adequadamente os elementos de evidenciação voluntária capazes de traduzir a influência da empresa sobre o ônus de fontes de financiamento.

Diante dos resultados encontrados e tendo em vista a elevada frequência de empresas que utilizam o juro sobre capital próprio como alternativa aos dividendos, tem-se que a utilização das despesas com juros presentes na DVA pode ser utilizada para realização de futuras investigações. Essas investigações podem relacionar o custo da dívida à diversificação de fontes de financiamento, estrutura de governança corporativa e qualidade da informação contábil. Estudos posteriores podem buscar identificar elementos de evidenciação voluntária que, sob a ótica de instituições credoras, são interpretados como sinalização de práticas que podem induzir a diminuição do ônus de fontes de financiamentos.

Embora os resultados deste estudo não apresentem potenciais vieses em favor de empresas com níveis baixos ou elevados de custo de dívida, tendo em vista que a análise de dados foi conduzida resguardando-se o exame do reflexo de empresas com comportamentos desviantes, trata-se de um painel curto de dados. Assim, o delineamento do corte de tempo da pesquisa representa um fator de limitação do estudo.

\section{REFERÊNCIAS}

ADKINS, L. Using Gretl for Principles of Econometrics. Oklahoma State University, Department of Economics and Legal Studies in Business, 2014.

AHMED, A. S.; BILLINGS, B. K.; MORTON, R. M.; STANFORD, M. The role of accounting conservatism in mitigating bondholder-shareholder conflicts over dividend policy and in reducing debt costs. The Accounting Review, v. 77, n. 4, p. 867-890, 2002.

ANDERSON, R. C.; MANSI, S. A.; REEB, D. M. Founding family ownership and the agency cost of debt. Journal of Financial Economics, v. 68, n. 2, p. 263-285, 2003.

ANDERSON, R. C.; MANSI, S. A.; REEB, D. M. Board characteristics, accounting report integrity, and the cost of debt. Journal of Accounting and Economics, v. 37, n. 3, p. 315$342,2004$.

BALL, R. International Financial Reporting Standards (IFRS): pros and cons for investors. Accounting and Business Research, International Accounting Policy Forum, p. 5-27, 2006.

BERTOMEU, J.; BEYER, A.; DYE, R. A. Capital structure, cost of capital, and voluntary disclosures. Accounting Review, v. 86, n. 3, p. 857-886, 2011.

BOTOSAN, C. A. Disclosure and the cost of capital: what do we know? Accounting \& Business Research, v. 36, p. 31-40, 2006.

BRASIL. Lei ${ }^{0}$ 6.404, de 15 de dezembro de 1976. Dispõe sobre as Sociedades por Ações. Diário Oficial [da] República Federativa do Brasil. Brasília. Disponível em: $<$ http://www.planalto.gov.br/ccivil_03/leis/L6404compilada.htm>. Acesso em: 11/06/2017. 
BRASIL. Lei n 9.249, de 26 de dezembro de 1995. Altera a legislação do imposto de renda das pessoas jurídicas, bem como da contribuição social sobre o lucro líquido, e dá outras providências. Diário Oficial [da] República Federativa do Brasil. Brasília. Disponível em: $<$ http://www.planalto.gov.br/ccivil_03/leis/L9249.htm>. Acesso em: 11/06/2017.

CHEN, D. Classified boards, the cost of debt, and firm performance. Journal of Banking \& Finance, v. 36, n. 12, p. 3346-3365, 2012.

CONSONI, S.; COLAUTO, R. D. Divulgação voluntária no contexto da convergência às Normas Internacionais de Contabilidade no Brasil. Revista Brasileira de Gestão de Negócios, v. 18, n. 62, p. 658-677, 2016.

COSENZA, J. P. A eficácia informativa da demonstração do valor adicionado. Revista Contabilidade \& Finanças, Edição Comemorativa, p. 7-29, 2003.

DEPOERS, F. A cost benefit study of voluntary disclosure: some empirical evidence from French listed companies. European Accounting Review, v. 9, n. 2, p. 245-263, 2000.

DYE, R. A. An evaluation of "essays on disclosure" and the disclosure literature in accounting. Journal of Accounting and Economics, v. 32, n. 1, p. 181-235, 2001.

EASLEY, D.; O'HARA, M. Information and the cost of capital. The Journal of Finance, v. 59, n. 4, p. 1553-1583, 2004.

FIELD, A. Descobrindo a estatística usando o SPSS-2. Bookman Editora, 2009.

FRANCIS, J.; KHURANA, I.; PEREIRA, R. Disclosure incentives and effects on cost of capital around the world. The Accounting Review, v. 80, p. 1125-1162, 2005.

GIBBINS, M.; RICHARDSON, A.; WATERHOUSE, J. The management of corporate financial disclosure: opportunism, ritualism, policies, and processes. Journal of Accounting Research, v. 28, n. 1, p. 121-143, 1990.

GUJARATI, D. N.; PORTER, D. C. Econometria básica. 5 ed. São Paulo: AMGH Editora, 2011.

HAIR, J. F.; ANDERSON, R. E.; TATHAM, R. L.; BLACK, W. C. Análise multivariada de dados. 5 ed. Porto Alegre: Bookman, 2005.

HEALY, P.; PALEPU, K. Information asymmetry, corporate disclosure and capital markets: a review of empirical disclosure literature. Journal of Accounting and Economics, v. 31, p. 405-440, 2001.

HUGHES, J. S.; LIU, J. Information asymmetry, diversification, and cost of capital. Accounting Review, v. 82, n. 3, p. 705-729, 2007.

IUDÍCIBUS, S. D.; MARTINS, E.; GELBCKE, E. R.; SANTOS, A. D. Manual de contabilidade societária. São Paulo: Atlas, 2010. 
LIMA, G. A. S. F. Nível de evidenciação x custo da dívida das empresas brasileiras. Revista Contabilidade \& Finanças, v. 20, n. 49, p. 95-108, 2009.

LEVINE, D. M.; STEPHAN, D.; KREHBIEL, T. C.; BERENSON, M. L. Estatística: teoria e aplicações-usando Microsoft Excel em português. Rio de Janeiro: LTC, 2005.

LOPES, A. B.; ALENCAR, R. C. Disclosure and cost of equity capital in emerging markets: The Brazilian case. The International Journal of Accounting, v. 45, n. 4, p. 443-464, 2010.

MURCIA, F. D.; SANTOS, A. Discretionary-based disclosure: evidence from the Brazilian market. BAR - Brazilian Administration Review, v. 9, n. 1, p. 88-109, 2012.

MARTINS, H. C.; TERRA, P. R. S. Maturidade do endividamento, desenvolvimento financeiro e instituições legais: análise multinível em empresas latino-americanas. Revista de Administração, v. 50, n. 3, 381-394, 2015.

MAZUMDAR, S. C.; SENGUPTA, P. Disclosure and the loan spread on private debt. Financial Analysts Journal, v. 61, n. 3, p. 83-95, 2005.

PITTMAN, J. A.; FORTIN, S. Auditor choice and the cost of debt capital for newly public firms. Journal of Accounting and Economics, v. 37, n. 1, p. 113-136, 2004.

SALOTTI, B. M.; YAMAMOTO, M. M. Divulgação voluntária da demonstração dos fluxos de caixa no mercado de capitais brasileiro. Revista Contabilidade \& Finanças, v. 19, n. 48, p. 37-49, 2008.

SANTOS, A. Quem está pagando juros sobre capital próprio no Brasil? Revista Contabilidade \& Finanças, v. 18, p. 33-44, 2007.

SANTOS, A.; SALOTTI, B. M. Juros sobre o capital Próprio: Pesquisa empírica para avaliação do nível de conhecimento das empresas sobre sua utilização. Contabilidade, Gestão e Governança, v. 10, n. 2, p. 97-118, 2009.

SENGUPTA, P. Corporate disclosure quality and the cost of debt. Accounting Review, v. 73, n. 4, p. 459-474, 1998.

SHLEIFER, A.; VISHNY, R. W. A survey of corporate governance. Journal of Finance, $\mathrm{n}$. 52, p. 737-783, 1997.

SILVEIRA, A. M.; PEROBELLI, F. F. C.; BARROS, L. A. B. C. Governança corporativa e os determinantes da estrutura de capital: evidências empíricas no Brasil. Revista de Administração Contemporânea, v. 12, n. 3, p. 763-788, 2008.

VERRECCHIA, R. E. Essays on disclosure. Journal of Accounting and Economics, v. 32, n. 1-3, p. 97-180, 2001.

WOOLDRIDGE, J. M. Introdução à econometria: uma abordagem moderna. São Paulo: Pioneira Thomson Learning, 2006. 
YAMAMOTO, M. M.; SALOTTI, B. M. Informação contábil: estudos sobre a sua divulgação no mercado de capitais. São Paulo: Atlas, 2006.

XUAN, Z. H. A. O.; ZHANG, L.; YUWEI, S. O. N. G. Environmental information disclosure of listed company study on the cost of debt capital empirical data: based on Thermal Power Industry. Canadian Social Science, v. 10, n. 6, p. 88-94, 2014. 